\title{
Predictive factors for stone disease in patients with renal colic
}

\author{
Hakan Türk ${ }^{1}$, Sitkı Ün ${ }^{2}$ \\ ${ }^{1}$ Dumlupinar University, Evliya Celebi Training and Research Hospital, Department of Urology, Kutahya, Turkey; \\ 2 Sivas State Hospital, Department of Urology, Sivas, Turkey.
} \begin{abstract}
$\begin{array}{ll}\text { Summary } & \begin{array}{l}\text { Introduction: Many patients present to urol- } \\ \text { ogy and emergency departments for acute }\end{array}\end{array}$ renal colic complaints. There are many different imaging studies that can be used in patients with a pre-diagnosis of acute renal colic. In this study, we would like to assess the efficacy of using clinical and laboratory results in patients with flank pain complaint as a predictive factor of urinary system stone disease.

Materials and methods: All patients were assessed using spinal non-contrast complete abdominal computerized tomography and urine analysis. Presence of stones and their number and size were recorded.

Results: 516 patients who were included in the study were divided into 2 groups according to urinary stone presence. Group $1(n=388)$ consisted of patients with stones meanwhile patients in Group $2(n=128)$ were stone-free. According to these results, male sex, presence of microscopic hematuria, stone history in the family, nausea and emesis in addition to pain and accompanying urinary symptoms were detected as predictive factors in diagnosing urinary stone disease by multivariate analysis.

Conclusion: From our study results, we can conclude that uroflowmetry is a very useful tool in monitoring lower urinary system complaints.
\end{abstract}

KEY WORDS: Renal colic; Urolithiasis; Flank pain; Hematuria.

Submitted 15 February 2017; Accepted 23 April 2017

\section{INTRODUCTION}

Many patients come to urology and emergency room (ER) settings for acute renal colic complaints. Urolithiasis is diagnosed in about 3 to $5 \%$ of the general population. Patients with a history of previous urinary system stones have about a $50 \%$ of risk of recurrence in 10 -year periods $(1,2)$. In order to manage the possible long-term side effects, the cases should be treated and followed up using the most efficient and fastest methods using minimal ionizing radiation exposure. Proper treatment strategies and appropriate directions in those patients are essential. There are many different imaging studies that can be used in patients with a pre-diagnosis of acute renal colic. Moreover, physical examination findings as well as laboratory results can be a guide in diagnosis. In this study, we would like to assess the efficacy of using clinical and laboratory results in patients with flank pain complaint as a predictive factor in urinary system stone disease.

\section{Materials AND methods}

Patients who presented to our clinic between May 2015 and September 2016 with acute renal colic complaint with a possible diagnosis of urinary system stone disease were included in the study. All patients were assessed using spiral non-contrast complete abdominal computerized tomography (CT). The patients' age varied from 17 to 68 years. CT results and urinalysis results were all reviewed. Non-contrast CT imaging was performed using GE Lightspeed 16 Pro CT machine with a spiral setting. Presence of stones and their number and size were recorded. In addition, patient symptoms, family histories, patient histories and visual analogue scale (VAS) scores were all reviewed.

\section{RESULTS}

516 patients who were included in the study were divided into 2 groups according to urinary stone presence. Group $1(n=388)$ consisted of patients with stones meanwhile patients in Group $2(\mathrm{n}=128)$ were stonefree. Mean age in Group 1 was calculated as $38.53 \pm 20.8$ (17-68) meanwhile in Group 2, mean age was $32.3 \pm$ 18.8 (17-65). Male/female ratio in Group 1 was 248/140 and 64/64 in Group 2. Other findings are summarized on Table 1. According to these results, male sex, presence of microscopic hematuria, stone history in the family, nausea and emesis in addition to pain and accompanying urinary symptoms were detected as predictive factors in diagnosing urinary stone disease by multivariate analysis.

\section{Discussion}

Urinary stones cause severe colicky pain by the response of smooth muscle and by epithelial biological responses to a partial or complete obstruction and dilation of the urinary tract according to their localization and size. The pain is so severe that it usually requires ER admittance (3). Acute renal colic is one of the leading causes for ER admittance in our country, much like the rest of the world. About 7-9\% of all pain-related emergency calls in Europe is thought to be renal colic (4).

Although renal colic can be seen in all ages, it is more frequent in ages between 35-45 (5, 6). A study done by Uluocak et al. reported the mean age of patients with 
Table 1.

Demographics data and clinical measurement values.

\begin{tabular}{|c|c|c|c|c|}
\hline Parameters & $\begin{array}{c}\text { Group } 1 \\
(n=388)\end{array}$ & $\begin{array}{c}\text { Group 2 } \\
(n=128)\end{array}$ & $\begin{array}{c}\text { Univariate } \\
\mathrm{p} \text { value }\end{array}$ & $\begin{array}{l}\text { Multivariate } \\
\text { p value }\end{array}$ \\
\hline Mean age & 38.53 & 32.3 & 0.044 & \\
\hline Sex & & & 0.005 & 0.015 \\
\hline Male (n) (\%) & $248(63.9)$ & $64(50)$ & & \\
\hline emale (n) (\%) & 140 (36.1) & $64(50)$ & & \\
\hline Pain score (VAS) & 6.85 & 6.31 & 0.003 & 0.78 \\
\hline $1-4$ & 32 & 24 & & \\
\hline $5-8$ & 312 & 96 & & \\
\hline $9-10$ & 44 & 8 & & \\
\hline Need for painkillers & & & 0.104 & \\
\hline Yes & $348(76.3)$ & $108(23.7)$ & & \\
\hline No & $40(66.6)$ & $20(33.4)$ & & \\
\hline Er admittance for severe pain (n) (\%) & & $<0.0001$ & 0.121 & \\
\hline $\begin{array}{ll}\text { Yes } \\
\end{array}$ & $352(77.8)$ & $100(22.2)$ & & \\
\hline No & $36(56.2)$ & $28(43.8)$ & & \\
\hline Microscopic hematuria (n) (\%) & & & $<0.0001$ & $<0.0001$ \\
\hline $\begin{array}{ll}\text { Yes } \\
\end{array}$ & $344(79.6)$ & $88(20.4)$ & & \\
\hline No & $44(52.3)$ & $40(47.7)$ & & \\
\hline Stone history (n) (\%) & & & $<0.0001$ & 0.14 \\
\hline Yes & $164(87.2)$ & $24(12.8)$ & & \\
\hline No & $224(68.2)$ & $104(31.8)$ & & \\
\hline Stone surgery history (n) (\%) & & & 0.001 & 0.23 \\
\hline Yes & $52(92.8)$ & $4(7.2)$ & & \\
\hline $\begin{array}{ll}\text { No } \\
\end{array}$ & $336(73)$ & $124(27)$ & & \\
\hline Family history of stones (n) (\%) & & & 0.001 & 0.028 \\
\hline $\begin{array}{ll}\text { Yes } \\
\end{array}$ & $200(81.9)$ & $44(18.1)$ & & \\
\hline No & $188(69.1)$ & $84(30.9)$ & & \\
\hline Pain duration (days) & 5.28 & 11.9 & $<0.0001$ & 0.051 \\
\hline Nausea and emesis (+) & 208 & 80 & $<0.0001$ & $<0.0001$ \\
\hline Urinary symptoms (+) & 210 & 102 & $<0.0001$ & $<0.0001$ \\
\hline
\end{tabular}

acute renal colic to be 41 with no significant difference between the sexes (7). Another study done on a 213patient series reported the mean age of the patients as 40.9 (8). In our study, the mean age of the patients was calculated as 35.2 , which is similar to previous results found in the literature and there was no significant difference between the sexes.

When sexes are compared, there are different results reported in the literature. Although the majority of the studies report that males are more susceptible than females, recent studies report no more such difference $(6,7,9-11)$. However, in our study the ratio of male patients was significantly higher in the stone patient group $(63.9 \%$ vs $36.1 \%)$

If the kidney stone is obstructive in nature, it causes colic pain. Stones located in renal pelvis or calyxes causing a partial obstruction cause a dull pain on lumbar region. Renal colic is a result of stones stretching the ureter and collecting system and resulting in hyperperistalsis. Kidney capsule stretching causes a dull pain which is not in colicky. About 60-95\% of patients with flank pain in acute colic fashion have ureter stones $(5,12)$. Local occurrences such as mucosal irritation, inflammation, edema and hyperperistalsis also cause pain. Especially edema formation can cause colicky pain by stretching free nerve endings. There are no studies found in the literature which uses visual analogue scale (VAS) as a predictive factor in urinary stone disease. Likewise in our study, we did not find a significant difference in terms of pain severity between stone patients and stone-free patients. Hematuria can be seen as a result of traumatizing effect of stones in calyx or pelvis mucosa. Most patients have microscopic hematuria. Macroscopic hematuria can manifest as transient hematuria or "tea-colored" urine (4, 6, 13, 14). However, absence of hematuria does not rule out urinary stone disease. A study reported hematuria occurrence on $72.2 \%$ in stone patients (6). In our study, we observed a significantly higher presence of both microscopic and macroscopic hematuria in stone patients compared to stone-free patients.

Lifetime risk for stone disease is around 10\% for every person in the general population and it is reported 2 times more in males compared to females. Ten and 20-year recurrence rates for stone disease increase from $50 \%$ to $75 \%$. Latest studies report a significant increase in prevalence both in females and the general population $(15,16)$. In our study, previous stone history or previous stone-related surgery were found to be higher in patients with stones, however, they were not found to be statistically significant. We think this is probably due to the low number of patients included in the study. For those with a history of passing kidney stones in the family, the risk of passing kidney stones rises by two folds compared to normal population.

This occurs 2-3 folds more frequently in men than women $(5,17)$. Similarly, we also found out that stone detection rates in patients with family history of renal stones were significantly higher.

Symptoms such as nausea or emesis can accompany acute flank pain. This is thought to be a result of overstimulation of celiac ganglion $(4,5)$. In our study, patients with nausea and emesis complaints had a significantly higher rate of stones detected. Assessment of additional symptoms in patients with flank pain can be helpful in diagnosis.

Ureter stones show symptoms by placement of the stone into ureter. Pain can vary according to the localization of the stone. In proximal ureter stones, intermittent lumbar pain (colic) is usually seen. As the stone passes towards lower pelvis, the pain spreads to abdominal area. In stones located in ureteral end, the pain spreads towards the groin and inguinal area. Vesical irritability symptoms can be seen in stones located in ureterovesical junction (2). In our study, patients with voiding symptoms caused by vesical irritability have a significantly higher rate of urinary stone disease diagnosis.

Even though there are no similar studies found in the literature, our study results showed a significantly higher detection of urinary stone disease in patients who came 
to ER early for pain. This is probably due to the increased severity of stone-related colic pain compared to other colic pain causes.

One of the limitations of our study is the low number of patients. However, we still think that our study has a significant value because it takes into account clinical and laboratory results of patients in the assessment of renal colic. We also think that the parameters used in our study can be developed into a scoring system with prospective studies with much larger patient groups. Therefore, our study can be a significant foundation stone in this matter.

\section{Conclusion}

In renal colic cases, the superiority of non-contrast sequential spiral CT over other imaging methods is clear due to its speed, accuracy and ability to show non-urinary system related intrabdominal pathologies; especially in ER settings. Presence of stone history in the family, microscopic hematuria detection in urinalysis and presence of voiding symptoms in patient can also indicate CT imaging for diagnosis and treatment assessment. However, stones are not detected in all patients with flank pain complaints.

\section{REFERENCES}

1. Ahmad NA, Ather MH, Rees J. Unenhanced helical computed tomography in the evaluation of acute flank pain. Int J Urol. 2003; 10:287.

2. Portis A, Sundaram C. Diagnosis and Initial Management of Kidney Stones. Am Fam Physican. 2001; 63:1329-38.

3. Labrecque M, Dostaler LP, Rousselle R, et al. Efficacy of nonsteroidal anti-inflammatory drugs in the treatment of acute renal colic. A meta-analysis. Arch Intern Med. 1994; 154:1381-7.

4. Müslümanoglu AY, Tepeler A. Renal kolik, tanı ve tedavisi. Marmara Medical Journal. 2008; 21:187-92.

5. Walsh PC, Retik AB, Vaughan ED Jr, Wein AJ (Editors).
Campbell's Urology. In: Menon M, Resnick MI. Urinary lithiasis: etiology, diagnosis, and medical management. 8th Edition, Philadelphia, Saunders, 2002, p. 3227-92.

6. Duran L, Acar E, Celenk Y, et al. Evaluation of patients presenting with renal colic in emergency department. Kocatepe Medical Journal. 2014; 15:274-8.

7. Uluocak N, Erdemir F, Atılgan D, ve ark. Tokat ilinde üriner sistem tas hastaligl prevalansi. Turkish Journal of Urology. 2010; 36:81-6.

8. Temeltas G, Asan Ç, Müezzinoglu T, Büyüksu C. An evaluation of the efficacy of lornoxicam in acute renal colic treatment. Inönü Universitesi Tip Fakültesi Dergisi 2008; 15:1-3.

9. Akıncı H. Karabük devlet hastanesine basvuran ürolojik acil olguların analizi. Uludag Üniversitesi Tip Fakültesi Dergisi 2009; 35:17-20.

10. Aktas C, Yencilek E, Ay D, et al. Comparison of computerized spiral tomography with ultrasonography for detection of ureteral calculi. Türkiye Acil Tip Dergisi 2010; 10:12-4.

11. Yigit Ö, Isık S. Seasonal distribution of renal colic visits to emergency department. Türkiye Acil Tip Dergisi. 2008; 8:110-3.

12. Federle M, Fishman E, Jeffrey B, Anne V. Pocket radiolologistabdominal. $2^{\text {nd }} e d$. Salt Lake City: Amirsys-W.B. Saunders, 2003; $p$. 305-7.

13. Tanagho E, McAninch J. Smith Genel Üroloji. 17.baskı. Istanbul: Nobel, 2009; p.1-254.

14. Eskelinen M, Ikonen J, Lipponen P. Usefulness of history-taking, physical examination and diagnostic scoring in acute renal colic. Eur Urol. 1998; 34:467-73.

15. Pearle MS, Calhoun EA, Curhan GC. Urologic Diseases of America Project. Urologic diseases in America project: urolithiasis. J Urol. 2005; 173:848-57.

16. Scales CD Jr, Curtis LH, Norris RD, et al. Changing gender prevalence of stone disease. J Urol. 2007; 177:979-82.

17. Atug F, Canoruç N. Tekrarlayan üriner sistem kalsiyum taslarının metabolik degerlendirmesi ve medikal yaklagımlar. Dicle Tup Dergisi 2006; 33:48-52.

\section{Correspondence}

Hakan Türk, MD, Specialist in Urology (Corresponding Author) hkntrk000@gmail.com

Dumlupinar University, Evliya Celebi Training and Research Hospital, Department of Urology. Kutahya, Turkey

Sttkı Un, MD, Specialist in Urology

sitki@doctor.com

Sivas State Hospital, Department of Urology, Sivas, Turkey 